\title{
Development and Testing of Different Models of Coconut Dehusker
}

\author{
S.B. Patil*, S.G. Mane, A.S. Bhalerao, R.D. Patil and R.S. Shelar \\ Dr. D. Y. Patil college of Agricultural Engineering and Technology, \\ Talsande Dist: Kolhapur (M. S.)-416 112, India \\ *Corresponding author:
}

\section{A B S T R A C T}

The existing models of coconut dehusking machines are pull type and suitable for right handed operators only. Therefore sitting models (pull and push type) suitable for both left handed and right handed operators were developed and the performance of newly developed both the models of coconut dehusker was tested on the basis of output capacity and dehusking efficiency. The tests were conducted at Department of Farm Machinery and Power Engineering, Dr. D. Y. Patil C.A.E.T, Talsande, Dist: Kolhapur (MS) in Sept.2016. The results shown that an output capacity of both pull type and push type coconut dehusker with left handed operator having the handle at left hand side, (LOLD) was 35.35 $\%$ and $34.87 \%$ higher than left handed operator having the handle at right hand side (LORD) respectively, which confirmed the provision of handle at left hand side had $34.87 \%$ to $35.35 \%$ increase in output capacity of coconut dehusking. In case of LOLD and RORD an output capacity of push type coconut dehusker was $7.73 \%$ and $8.87 \%$ higher than the pull type coconut dehusker. An output capacity of sitting model (pull type) of coconut dehusker $(73.33$ nuts $/ \mathrm{h}$ ) was $12.81 \%$ more than the existing standing model of (pull type) coconut dehusker. Whereas, the dehusking efficiency of existing and all the newly developed of sitting models of coconut dehusker was at par and found in the range of $94.57 \%$ to $95.86 \%$.

\section{Introduction}

Coconut is grown in more than 86 countries worldwide in 12.5 million hectares of land which constitute about 0.7 per cent of the net crop of the world (Theerkhapathy et al., 2014). India is the third largest coconut producing country, after Indonesia and the Philippines, having an area of about 1.78 million hectares under the crop. India's annual production is about 7562 million nuts with an average of 5295 nuts/hectare (Shashikumar et al., 2014). Traditionally, the economic importance of coconut was laid on its nourishing water, kernel, copra, oil and coir, but laying emphasis on value addition and product diversification is widening the spectrum of its economy. Separation of its husk from the nut (dehusking) constitutes the, most difficult and dangerous operation in its processing. Presently, coconut dehusking with existing and popularly used models of coconut dehusking machines need the worker to bend from waist, to bring the coconut sharply down 
into the blade, twisting to one side, loosen the husk and detaching the fiber from the shell. This action is repeated several times until the entire fibers are removed. As the dehusking is to be done in standing/bending posture, the work becomes not only hard but also causes pain in waist and legs. Also all the existing models of coconut dehusking machines are pull type and suitable for right handed operators only. Therefore a study was under taken to develop and test the sitting models (pull and push type) suitable for both left handed and right handed operators.

\section{Materials and Methods}

\section{Development considerations}

An efforts were made to develop different models of sitting type manual operated (pull type and push type) coconut dehusker suitable to operate by both left hand and right handed operator. Following points were considered for the development of different models of coconut dehusker.

1) It should be able to dehusk different size coconuts viz. small medium and large.

2) It should be easy to operate.

3) It should be fabricated by using locally available material.

4) It should be compact.

5) It should have less number of parts to reduce cost and complexity.

6) It should have minimum cost.

\section{Working of coconut dehusker}

The different models of sitting type manual operated coconut dehusker (pull type and push type) suitable to operate by both left hand and right handed operator were developed in the Dept. of Farm Machinery and Power Engineering, Dr. DYP CAET, Talsande Dist: Kolhapur (MS). The working of different developed models of coconut dehusker is explained as under

\section{Pull type coconut dehusker}

In order to dehusk the coconut, the coconut is impaled with both hands on the blades which were initially in juxtaposed position. Then coconut was held stable on the blades by one hand while other hand is used to pull the handle. As the handle is pulled upward the movable blade opens from the juxtaposed position and a small portion of the coconut husk is removed from coconut. This procedure needs to be repeated for 3-4 times for complete removal of husk from the coconut. For efficient dehusking, coconut shall be impaled horizontally on the wedge blades. Operator can adjust the height of the seat of stool to meet his comfort level. The handle can be attached either on the left hand side or right hand side as per the demand of the operator (Fig. 1a and 1b).

\section{Push type coconut dehusker}

The basic working of push type dehusker is similar to that of pull type dehusker except the movement of handle. The coconut is impaled with both hands on the blades which were initially in juxtaposed position, and after impaling coconut, it was held stable by one hand while the other hand is used to push the handle downwards. Due to pushing the handle downward, the movable blade opens from the juxtaposed position, to dehusk the coconut. Similar to the pull type coconut dehusker, the handle can be attached either on the left hand side or right hand side as per the demand of the operator (Fig. 2a and 2b).

\section{Existing coconut dehusker}

The working of existing model of coconut dehusker is similar to that of pull type dehusker. The operator has to perform the work in standing posture by little bending in a waist. The existing model was pull type and had handle at right hand side only with no 
provision of attaching the handle either on the left hand side or right hand side as per the demand of the operator (Fig. 3a and 3b).

\section{Performance testing of coconut dehusker}

The performance of newly developed both the models of coconut dehusker was tested on the basis of output capacity and dehusking efficiency. The tests were conducted at Department of Farm Machinery and Power Engineering, Dr. D.Y.P.C.A.E.T, Talsande, in Sept.2016. The properties of coconuts used for the study are given in Table 1 .

Two sitting models of coconut dehusker (pull type and push type) and one traditional standing type coconut dehusker were tested by using left handed as well as right handed operators. Three left handed and three right handed operators were used for the testing. The procedure was replicated 3 times.

\section{Output capacity}

The total dehusking time included time for coconut impaling, splitting time, unloading time and time required to remove the loosen husk. The time required for dehusking 20 coconuts with each model operated by left handed as well as right handed operators was recorded and The coconuts dehusking rate was calculated as:

Output capacity (Nuts/hr) =

Number of coconut dehusked Time,hr.

\section{Dehusking efficiency}

Initially, the husk was weighed on the weighing balance after dehusking on the dehusker. Then the remaining husk present in coconut was removed completely from the dehusked coconut manually to know the total weight of husk.
The dehusking efficiency was calculated by the following formula.

Dehusking efficiency $=$

$\frac{\text { weight of husk obtained after dehusking }}{\text { weight of total husk present in coconut }} \times 100 \ldots$.

\section{Results and Discussion}

\section{Performance evaluation of newly developed coconut dehusker}

The performance of newly developed sitting models of coconut dehusker (pull type and push type) and traditional standing type coconut dehusker were tested by using three left handed and three right handed operators. The observations and the values of performance parameters calculated are given in Table 2.

\section{Performance of sitting model of pull type dehusker}

The existing models of coconut dehusker have the handle to right hand side only. No coconut dehusker was found with left hand side handle. Therefore, the performance of sitting models (pull type) of coconut dehusker with handle at left hand side, operated by both left handed and right handed operator was studied and compared with sitting models (pull type) coconut dehusker having the handle at right hand side and existing standing model (pull type) of coconut dehusker (EXD) using right handed operator.

The results of performance testing are presented in Figure 4 which shows that, sitting models (pull type) coconut dehusker operated by right handed operator having the handle at right hand side (RORD) has highest output capacity (73.33 nuts/h) and it is $12.81 \%$ higher than existing standing model (pull type) of coconut dehusker using right handed operator. 
At the same time it can be seen from the Figure 2 that, the output capacity of left handed operator having the handle at left hand side, (LOLD) is 71.44 nuts/h, which was at par with the output capacity of right handed operator having the handle at right hand side (RORD). Also the output capacity of left handed operator having the handle at left hand side, (LOLD) was $35.35 \%$ higher than coconut dehusker with left handed operator having the handle at right hand side (LORD) which confirmed the provision of handle at left hand side had $35.35 \%$ increase in output capacity of coconut dehusking.

The coconut dehusking efficiency of all the cases viz. left handed operator having the handle at left hand side (LOLD), left handed operator having the handle at right hand side (LORD), right handed operator having the handle at right hand side (RORD), and existing standing model (pull type) of coconut dehusker (EXD) using right handed operator was in the range of 94.57 to $95.86 \%$.

The higher output capacity of coconut dehusking in case of sitting model was might be due to less pain and fatigue experienced by operator in sitting posture than the standing posture which maintained uniform rate of coconut dehusking and resulted in higher output capacity. Also higher output capacity in case of right handed operator having the handle at right hand side, (RORD) was might be due to use right hand with more strength for pulling the handle and left hand with comparatively less strength for holding the coconut on the blades of dehusker which caused delayed response of both the hand with respect to each other and required more time to dehusk the coconut. Similarly, in case of left handed operator having the handle at left hand side, (LOLD) was might be due to comparatively more strength in left hand used for pulling the handle than right hand used for holding the coconut on the blades of dehusker.

\section{Performance of sitting model push type dehusker}

The performance of sitting models (push type) of coconut dehusker with handle at left hand side, operated by both left handed and right handed operator was studied and compared with sitting models (push type) coconut dehusker having the handle at right hand side and existing standing model (pull type) of coconut dehusker (EXD) using right handed operator.

The results of performance testing are presented in Figure 3 which shows that, sitting models (push type) coconut dehusker operated by right handed operator having the handle at right hand side (RORD) has highest output capacity ( 79 nuts/h) and it is $21.54 \%$ higher than existing standing model (pull type) of coconut dehusker using right handed operator. At the same time it can be seen from the Figure 5 that, the output capacity of left handed operator having the handle at left hand side, (LOLD) is 77.78 nuts/h, which was at par with the output capacity of right handed operator having the handle at right hand side (RORD). Also the output capacity of left handed operator having the handle at left hand side, (LOLD) is $34.87 \%$ higher than coconut dehusker with left handed operator having the handle at right hand side (LORD) which confirms the provision of handle at left hand side has $34.87 \%$ increase in output capacity of coconut dehusking.

The coconut dehusking efficiency of all the cases viz. left handed operator having the handle at left hand side (LOLD), left handed operator having the handle at right hand side (LORD), right handed operator having the handle at right hand side (RORD), and existing standing model (pull type) of coconut dehusker (EXD) using right handed operator was in the range of $94.57 \%$ to $95.39 \%$. 
The reasons for the higher output capacity of coconut dehusking in case of sitting model and an increase in output capacity in case of left handed operator having the handle at left hand side, (LOLD) are as postulated in section 3.1.1.

\section{Comparative performance of pull type and push type dehusker}

The performance of sitting models (pull type and push type) of coconut dehusker operated by both left handed and right handed operators by attaching the handle on either sides was studied and compared. The comparative performance is presented in Figure 4 shows that the output capacity of push type coconut dehusker was higher than the pull type coconut dehusker in each case viz. left handed operator having the handle at left hand side (LOLD), right handed operator having the handle at left hand side (ROLD), left handed operator having the handle at right hand side (LORD), right handed operator having the handle at right hand side (RORD). At the same time, an output capacity in case of LOLD and RORD was found at par and maximum for both the models (pull type and push type) of coconut dehusker. The reason for this is explained in section 3.1.1

In case of LOLD and RORD, an output capacity of push type coconut dehusker was $7.73 \%$ and $8.87 \%$ higher than the pull type coconut dehusker. In case of pull type dehusker, the frame needed additional force to be applied by the legs to make it stable. Whereas in case of push type dehusker the downward force applied on the handle (to push it for dehusking of coconut) added into the weight of the machine which increased ground reaction making the machine more stable during the operation and reduced the time required for dehusking. Hence the the output capacity of push type coconut dehusker was higher than the pull type coconut dehusker in all the cases studied. The coconut dehusking efficiency of all the cases studied was at par and found in the range of $94.57 \%$ to 95.86\% (Fig. 6).

\section{Effect of posture on performance of dehusker}

The existing standing model of coconut dehusker was pull type and the handle was provided to the right hand side of the dehusker. The existing standing model had no provision of connecting the handle to either sides. Therefore to know the effect of posture on performance of dehusker, the performance of sitting model of pull type coconut dehusker operated by right handed operator with handle to right hand side only was compared with the performance of existing standing model of coconut dehusker (Fig. 7).

The graph shows that, the output capacity of sitting model (pull type) of coconut dehusker (73.33 nuts/h) was $12.81 \%$ more than the existing standing model of coconut dehusker. Whereas, the dehusking efficiency of both the existing standing model and newly developed of sitting model (pull type) coconut dehusker was at par.

Table.1 Properties of coconuts used for the study

\begin{tabular}{|l|c|}
\hline Parameter & Value \\
\hline Variety & Banavali \\
\hline Weight of coconut $(\mathbf{g m})$ & 286 gm \\
\hline Roundness & 0.63 \\
\hline Sphericity & 0.798 \\
\hline Moisture content in husk (W.B) $(\%)$ & 23.73 \\
\hline
\end{tabular}


Table.2 The observations and the values of performance parameters of newly developed manually operated coconut dehusker

\begin{tabular}{|c|c|c|c|c|c|c|c|c|c|c|c|}
\hline \multirow{3}{*}{$\begin{array}{l}\text { Type of } \\
\text { Operator }\end{array}$} & \multirow{3}{*}{$\begin{array}{c}\text { Operator } \\
\text { No. }\end{array}$} & \multicolumn{5}{|c|}{ Coconut dehusking rate, (Coconuts/h) } & \multicolumn{5}{|c|}{ Coconut dehusking efficiency, $(\%)$} \\
\hline & & \multicolumn{2}{|c|}{$\begin{array}{c}\text { Pull Type } \\
\text { (sitting model) } \\
\text { with handle at }\end{array}$} & \multicolumn{2}{|c|}{$\begin{array}{c}\text { Push Type } \\
\text { (sitting model) } \\
\text { with handle at }\end{array}$} & \multirow{2}{*}{$\begin{array}{l}\text { Existing } \\
\text { model } \\
\text { (standing } \\
\text { model) }\end{array}$} & \multicolumn{2}{|c|}{$\begin{array}{c}\text { Pull Type } \\
\text { (sitting model) with } \\
\text { handle at }\end{array}$} & \multicolumn{2}{|c|}{$\begin{array}{c}\text { Push Type } \\
\text { (sitting model) } \\
\text { with handle at }\end{array}$} & \multirow{2}{*}{$\begin{array}{c}\text { Existing } \\
\text { model } \\
\text { (standing } \\
\text { model) }\end{array}$} \\
\hline & & LHS & RHS & LHS & RHS & & LHS & RHS & LHS & RHS & \\
\hline \multirow{7}{*}{$\begin{array}{c}\text { Left } \\
\text { Handed }\end{array}$} & \multirow[t]{2}{*}{ I } & 71 & 52 & 77 & 56 & 54 & 94.16 & 96.91 & 93.22 & 96.07 & 95.77 \\
\hline & & 69 & 54 & 74 & 58 & 52 & 96.62 & 96.64 & 94.51 & 95.68 & 94.62 \\
\hline & \multirow[t]{3}{*}{ II } & 71 & 51 & 77 & 59 & 56 & 97.65 & 94.76 & 95.77 & 92.68 & 91.88 \\
\hline & & 73 & 52 & 80 & 57 & 55 & 96.34 & 96.34 & 92.90 & 96.55 & 94.02 \\
\hline & & 68 & 54 & 76 & 59 & 51 & 94.32 & 95.05 & 94.53 & 96.00 & 96.05 \\
\hline & \multirow[t]{2}{*}{ III } & 74 & 51 & 78 & 61 & 53 & 91.93 & 94.15 & 94.36 & 96.70 & 94.48 \\
\hline & & 71 & 54 & 80 & 58 & 55 & 95.24 & 96.82 & 94.41 & 95.86 & 96.78 \\
\hline \multirow{8}{*}{$\begin{array}{c}\text { Right } \\
\text { Handed }\end{array}$} & I & 53 & 71 & 60 & 80 & 64 & 97.10 & 96.92 & 95.77 & 91.28 & 94.02 \\
\hline & \multirow[t]{3}{*}{ II } & 56 & 75 & 59 & 81 & 67 & 95.26 & 96.33 & 94.62 & 95.26 & 95.00 \\
\hline & & 53 & 73 & 62 & 82 & 65 & 94.94 & 96.50 & 96.05 & 96.91 & 96.91 \\
\hline & & 55 & 70 & 58 & 81 & 64 & 95.60 & 97.52 & 94.48 & 96.64 & 94.69 \\
\hline & \multirow[t]{3}{*}{ III } & 56 & 73 & 57 & 79 & 65 & 95.07 & 96.62 & 95.56 & 95.13 & 94.02 \\
\hline & & 52 & 75 & 58 & 77 & 67 & 91.28 & 95.13 & 96.07 & 91.16 & 96.05 \\
\hline & & 51 & 74 & 57 & 80 & 64 & 95.26 & 91.16 & 94.40 & 95.77 & 94.21 \\
\hline & Average & 56.33 & 73.33 & 58 & 79 & 65 & 94.21 & 95.86 & 94.80 & 95.01 & 95.22 \\
\hline
\end{tabular}




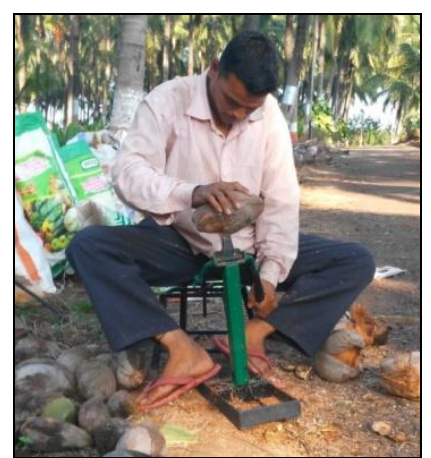

a. Left handled model

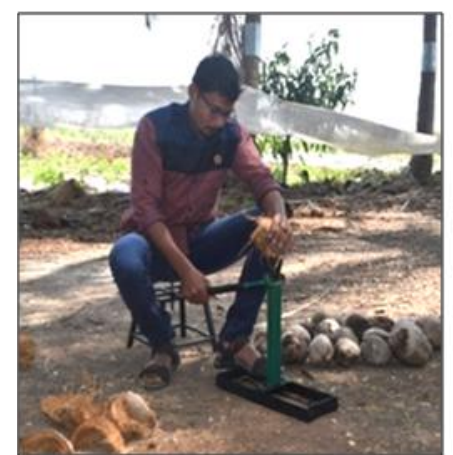

b. Right handled model

Fig. 1 Working of Pull type coconut dehusker

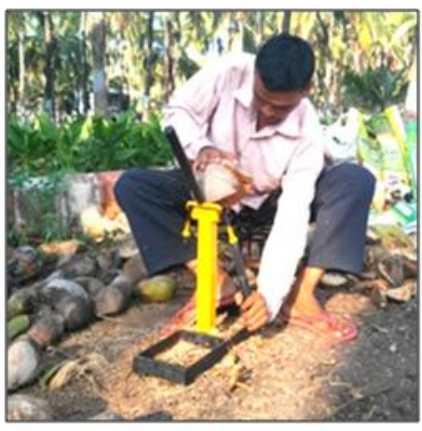

a. Left handled model

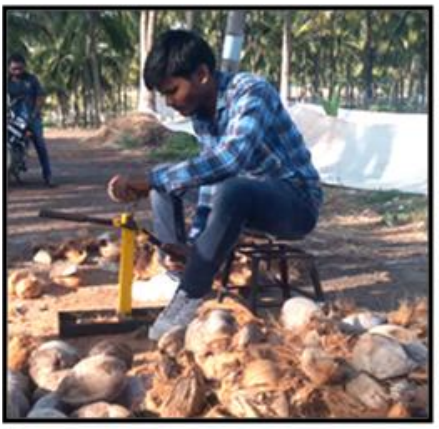

b. Right handled model

Fig. 2 Working of Push type coconut dehusker

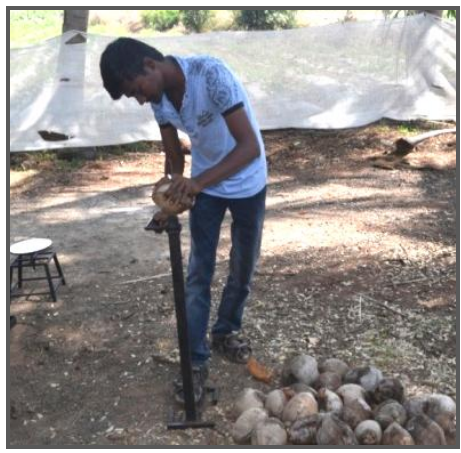

a. Left handled model

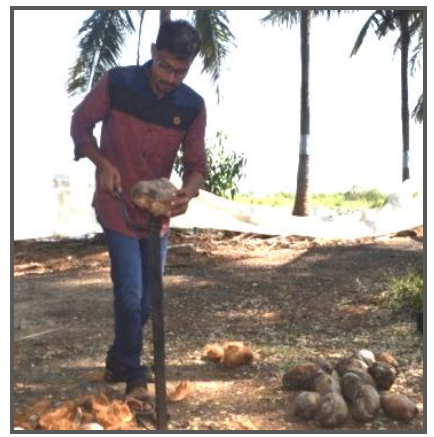

b. Right handled model

Fig. 3 Working of existing model coconut dehusker 
Fig.4 Performance of sitting model of pull type dehusker

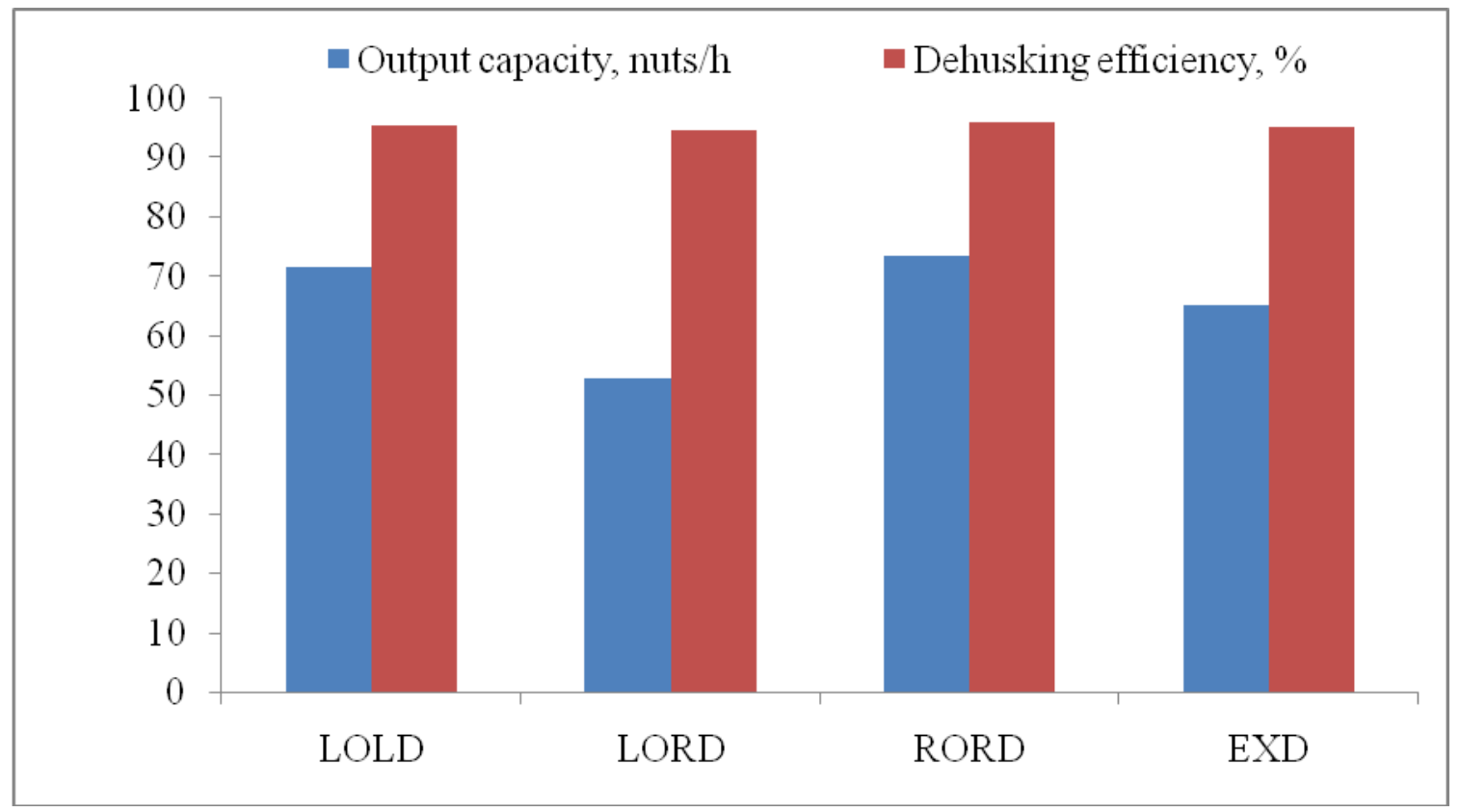

Fig.5 Performance of sitting model of push type dehusker

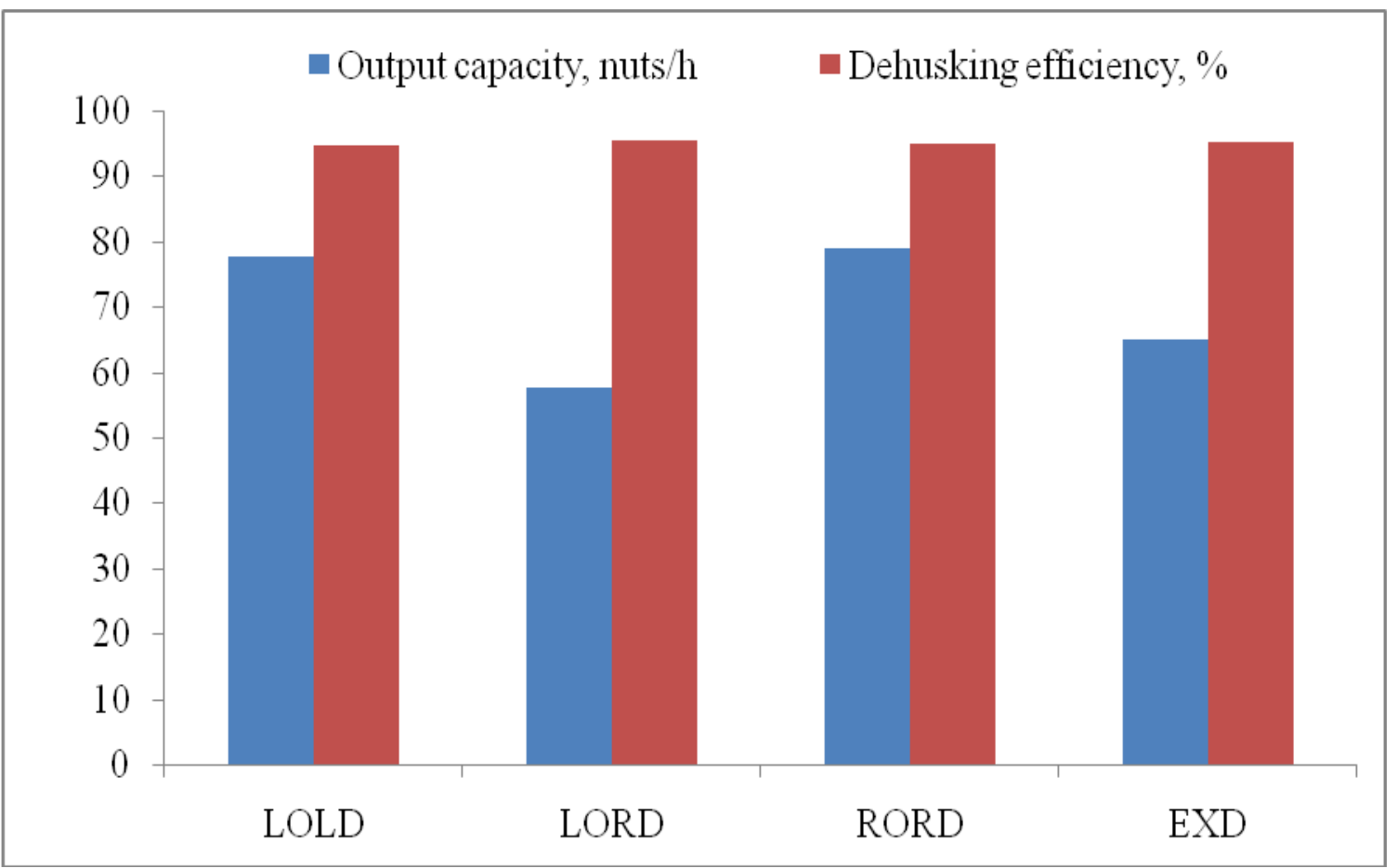


Fig.6 Comparative performance of pull type and push type dehusker

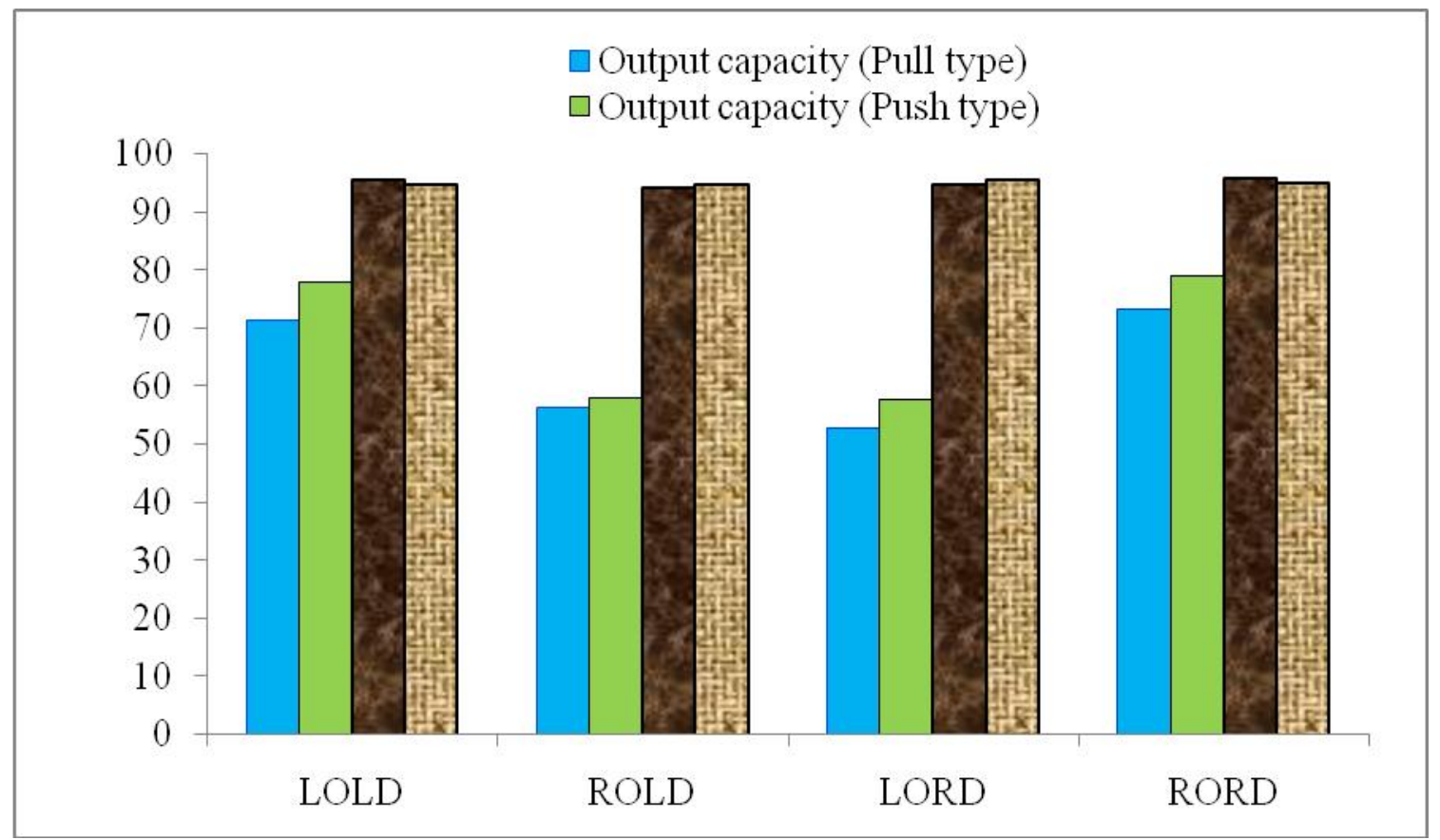

Fig.7 Effect of posture on performance of dehusker

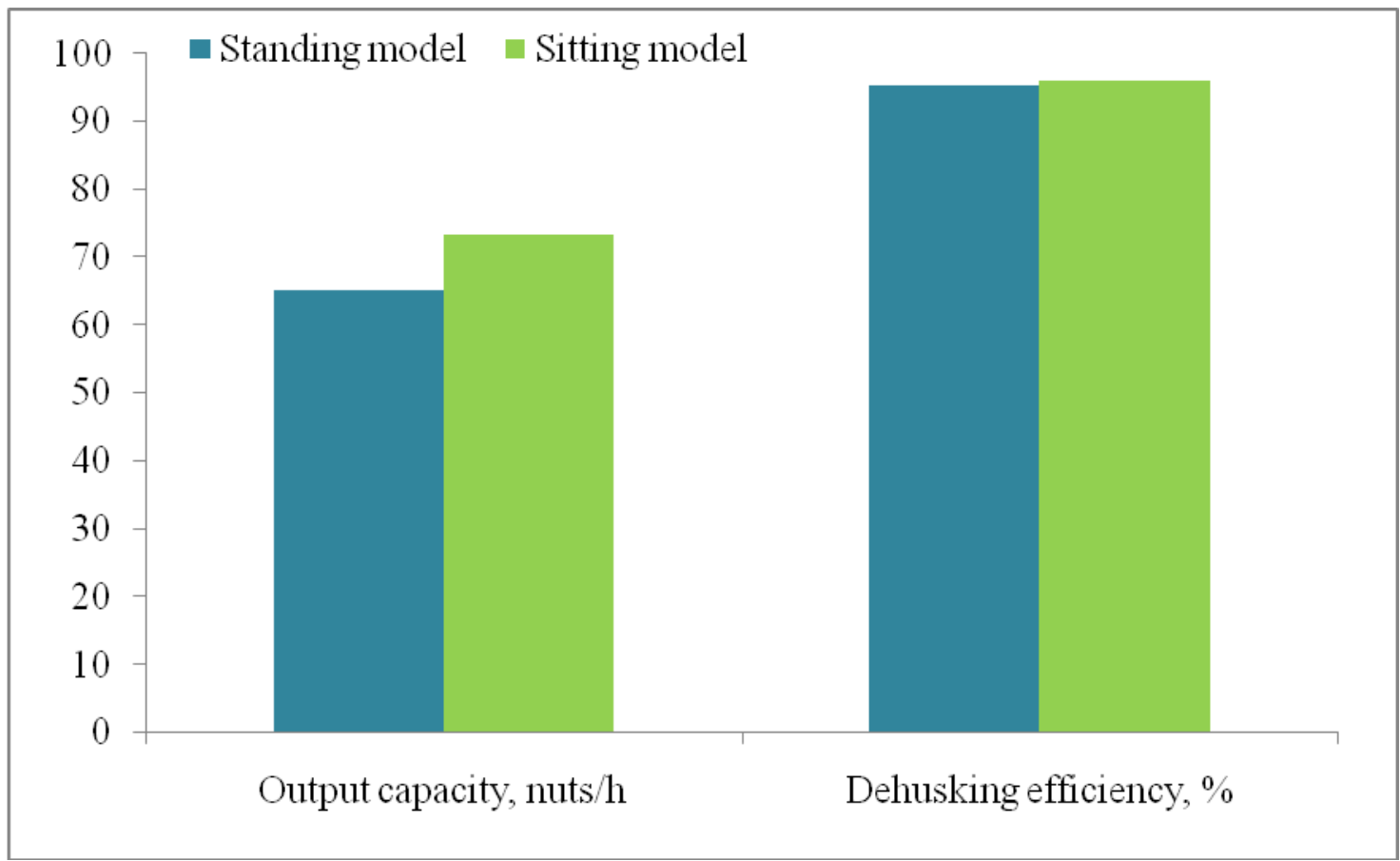


The more output capacity in case of sitting model (pull type) of coconut dehusker was mainly due to less fatigue caused due to more comfortable posture. In case of existing standing model of coconut dehusker the bending posture during dehusking caused more pain in back causing more fatigue and resulted in lower output capacity.

It is concluded that

An output capacity of both pull type and push type coconut dehusker with left handed operator having the handle at left hand side, (LOLD) was $35.35 \%$ and $34.87 \%$ higher than left handed operator having the handle at right hand side (LORD) respectively, which confirmed the provision of handle at left hand side had $34.87 \%$ to $35.35 \%$ increase in output capacity of coconut dehusking.

An output capacity in case of left handed operator having the handle at left hand side, LOLD and right handed operator having the handle at right hand side, RORD was found at par and maximum for both the models (pull type and push type) of coconut dehusker.

In case of left handed operator having the handle at left hand side, LOLD and right handed operator having the handle at right hand side, RORD, an output capacity of push type coconut dehusker was $7.73 \%$ and $8.87 \%$ higher than the pull type coconut dehusker.
An output capacity of sitting model (pull type) of coconut dehusker (73.33 nuts/h) was $12.81 \%$ more than the existing standing model of coconut dehusker. Whereas, the dehusking efficiency of existing and all the newly developed of sitting models of coconut dehusker was at par and found in the range of $94.57 \%$ to $95.86 \%$.

\section{References}

Patil, S. R. 2014. Development of power operated coconut dehusker. Unpublished M. Tech. (FMPE) thesis submitted to the Dr. Balasaheb Sawant Konkan Krishi Vidyapeeth, Dapoli, Maharashtra State (India).

Shashikumar, S. and Chandrashekar H.M. 2014. An analysis of production and marketing of coconut in Tumkur District, India. International Journal of Current Research and Academic Review. Volume 2 Number 10: 167175.

Theerkhapathy, S.S. and Chandrakumarmangalam S. 2014. Coconut processing industries: An outlook. Global Journal of Commerce and Management Perspective, Global Institute for Research and Education. Volume 3 (5): 219-221.

\section{How to cite this article:}

Patil, S.B., Mane, S.G., Bhalerao, A.S., Patil, R.D. and Shelar R.S. 2018. Development and Testing of Different Models of Coconut Dehusker. Int.J.Curr.Microbiol.App.Sci. 7(08): 10241033. doi: https://doi.org/10.20546/ijcmas.2018.708.115 